\title{
B7 - OPTIMIZATION OF HIGH PERFORMANCE LIQUID CHROMATOGRAPHY BY SIZE EXCLUSION AND REVERSED PHASE FOR HOMOGENEITY ANALYSIS OF RECOMBINANT HUMAN ERYTHROPOIETIN
}

Ingrid Pinheiro de Medeiros ${ }^{1}$, Hilton Jorge do Nascimento ${ }^{1}$, Eduardo da Silva Gomes ${ }^{1}$, Melissa Chamon Alves Premazzi ${ }^{1}$, Jaline Coutinho Silvério ${ }^{1}$, Erica Louro da Fonseca ${ }^{1}$, Daniel da Silva Guedes Jr. ${ }^{1}$

1. Bio-Manguinhos, Oswaldo Cruz Foundation, Quality Control, Rio de Janeiro, Brazil.

\section{Objectives}

Among the chromatographic methods advocated by the European Pharmacopoeia (E.P.) for the analysis of homogeneity of Recombinant Human Erythropoietin (rhEPO) stands the High Performance Liquid Chromatography by Size Exclusion (SEC-HPLC) and High Performance Liquid Chromatography by Reversed Phase (RP-HPLC). The aim of this study was to standardize and optimize the chromatographic methods in order to determine the purity, the presence of aggregates and the degradation products of rhEPO.

\section{Methods}

In accordance with E.P. some parameters were adjusted such as: analytical column, flow, eluents and gradient elution. For SEC-HPLC analysis of the rhEPO's candidate reference material (cMR) was used analytical column TSK Gel G2500 and for RP-HPLC analysis was used analytical columm Vydac C8 and Bakerbond WP octadecyl with a flow of 1.0 $\mu \mathrm{L} / \mathrm{min}$, injection volume $100 \mu \mathrm{L}$, pressure limit $10 \mathrm{mPa}$ and detection at $220 \mathrm{~nm}$ and $280 \mathrm{~nm}$. The analysis was performed with different concentrations of cMR and the results compared to BRP (Biological Reference Preparation of E.P.).

\section{Results}

The samples presented a single chromatographic peak with retention time and area equivalent between replicas of cMR and BRP. The area increases with the concentration of the sample, it is possible to set the limit of quantification and detection. Analysis was 
performed in less time compared to what is described by E.P. The integration of chromatographic peaks of the samples demonstrates purity percentage specifications as the E.P.

\section{Conclusion}

The standard and optimized techniques demonstrated to be effective and reproducible for purity and aggregates analysis, as well as to confirm the stability of rhEPO. Thus, such methods to be implemented in Quality Control routine of Bio-Manguinhos/Fiocruz, will enable a proper analysis of the rhEPO concentrated solution as its homogeneity and physicochemical characterization. 